\title{
Development of Home Fixed Mobile Convergence Gateway Solution for Smartphone App
}

\author{
Hyoung-Keun Park ${ }^{1 *}$ \\ $1^{*}$ Dept. of Electronic Engineering, Namseoul University, \\ 91 Daehak-ro Seonghwan-eup Sebuk-gu Cheonan-si, Chungnam-do, South Korea \\ phk315@nsu.ac.kr
}

\begin{abstract}
In this study, it is possible to install the application on the smartphone to the gateway where the domestic router and the VoIP terminal are combined according to the above-mentioned service change, and to use the wired home telephone through the gateway, and also to the $m V o I P$ service as a home terminal. The smart AP (Access Point) developed in this study is a terminal that integrates $A P+M T A+P B X+m V o I P$ function and developed $m V o I P$ to be used in WiFi and $3 G$ data network as well as LTE data network. The price of MTA (Media Telephony Adapter) and IP phone is cheap but it is limited by wired terminal and WiFi phone or pat phone without limit of calling area is not widely spread due to expensive terminal. Home FMC gateway targeted marketing positioning is a solution that uses wireless to lower the terminal price by using smart phones that users do not have any restriction on calling area. In accordance with the change of service, it is possible to install the application on the smartphone to the gateway where the domestic router and VoIP terminal are combined, and to use the landline phone through the gateway. Also, it is a combined terminal that combines the mVoIP service, Home FMC Gateway.
\end{abstract}

Keywords: Home Fixed Mobile Convergence Gateway, Smart Access Point, Mobile voice over IP, Private Branch Exchange

\section{Introduction}

Since the launch of iPhone around the world, the spread of smart phones has been rapidly shifting from PSTN-based voice calls to IP-based data communications. The existing voice service is also being replaced by mVoIP (mobile voice over IP) service based on IP. Typical mVoIP services include Israel Fring, Truphone in the UK, and Skype in the UK. In Korea, there are KakaoTalk and Line voice chat. However, most mVoIP services are regulated due to the drop in the Average Revenue Per Unit (ARPU) of the voice call service of the mobile carrier and are limited only by communication with the ID registered by the user. Also, ARPU of landline telephone service is decreasing due to convenience of direct call using address book stored in smartphone. Telephone ARPU of cable operators has been continuously declining. To improve this, WiFi phones and pad phones have been released, but they are not spreading due to the high price of terminals and the hassle of moving the smart phone address book back to the terminal. The wired communication environment in the home is an increasing tendency to use smart phones and laptops wirelessly by building a WiFi environment (wired / wireless router), and in the case of a telephone service, a VoIP terminal that deals with an existing circuit line is used $[1,2]$.

Received (October 15, 2017), Review Result (December 19, 2017), Accepted (January 15, 2018) 


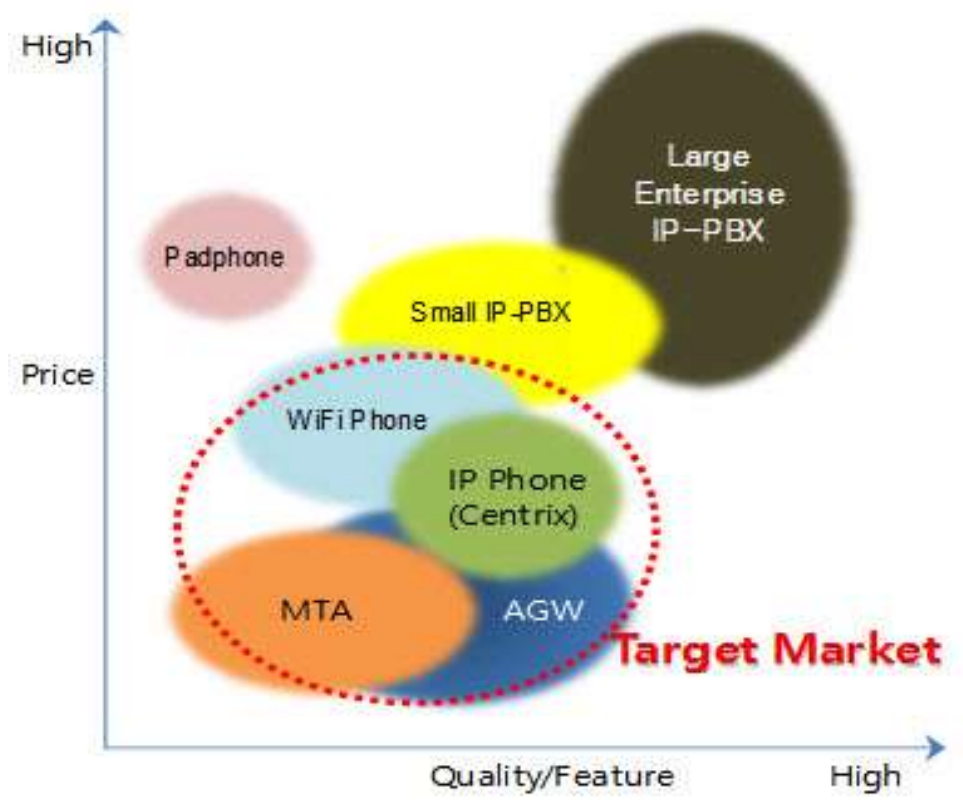

Figure 1. Home FMC Gateway Target Marketing Positioning

As shown in Figure 1, the price of MTA (Media Telephony Adapter) and IP phone is cheap but it is limited by wired terminal and WiFi phone or pat phone without limit of calling area is not widely spread due to expensive terminal. Home FMC gateway targeted marketing positioning is a solution that uses wireless to lower the terminal price by using smart phones that users do not have any restriction on calling area.

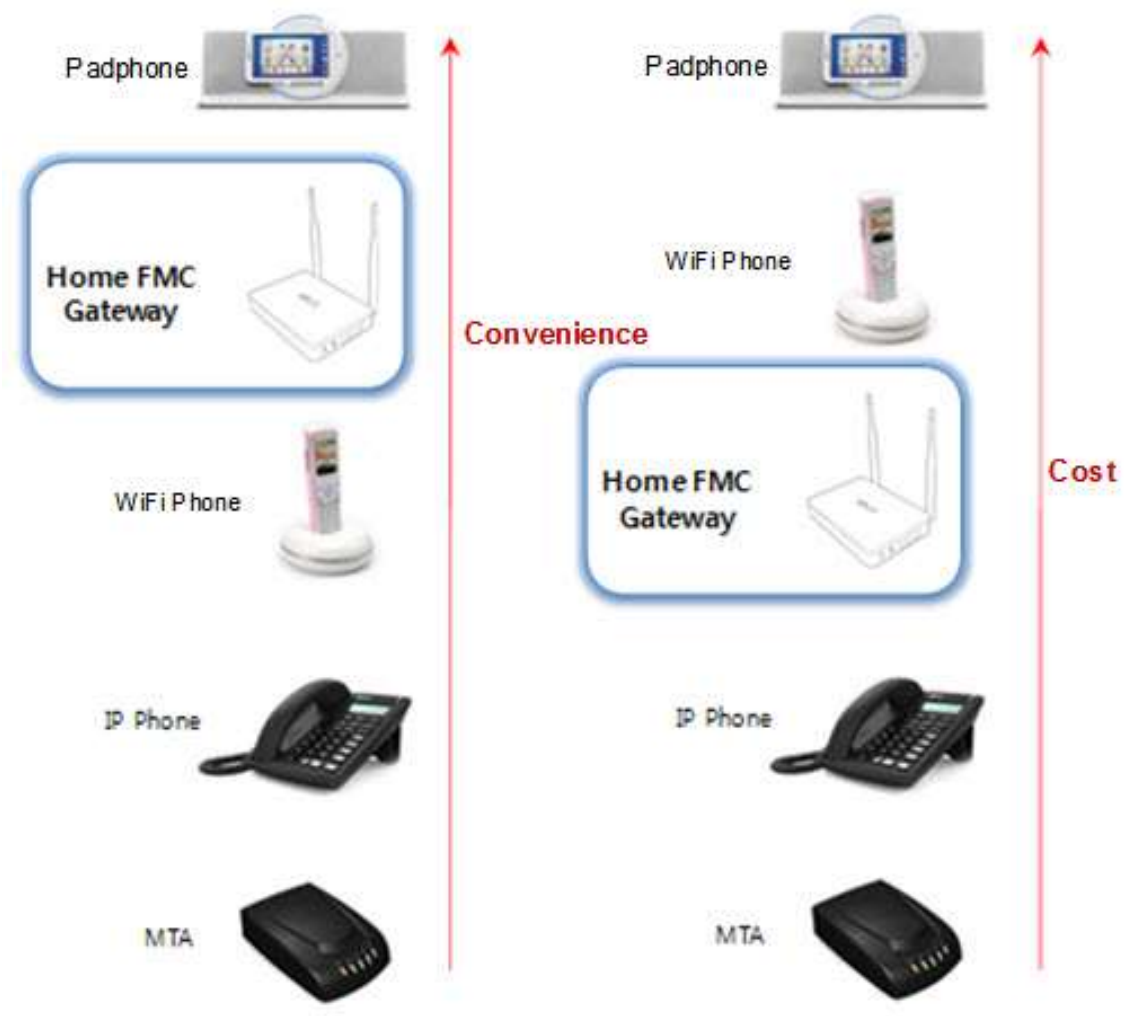

Figure 2. Convenience and Cost Positioning 


\section{Smart AP and DDNS Server}

In this study, it is possible to install the application on the smartphone to the gateway where the domestic router and the VoIP terminal are combined according to the above-mentioned service change, and to use the wired home telephone through the gateway, and also to the mVoIP service as a home terminal. The smart AP (Access Point) developed in this study is a terminal that integrates AP + MTA + PBX + mVoIP function and developed mVoIP to be used in $\mathrm{WiFi}$ and $3 \mathrm{G}$ data network as well as LTE data network.

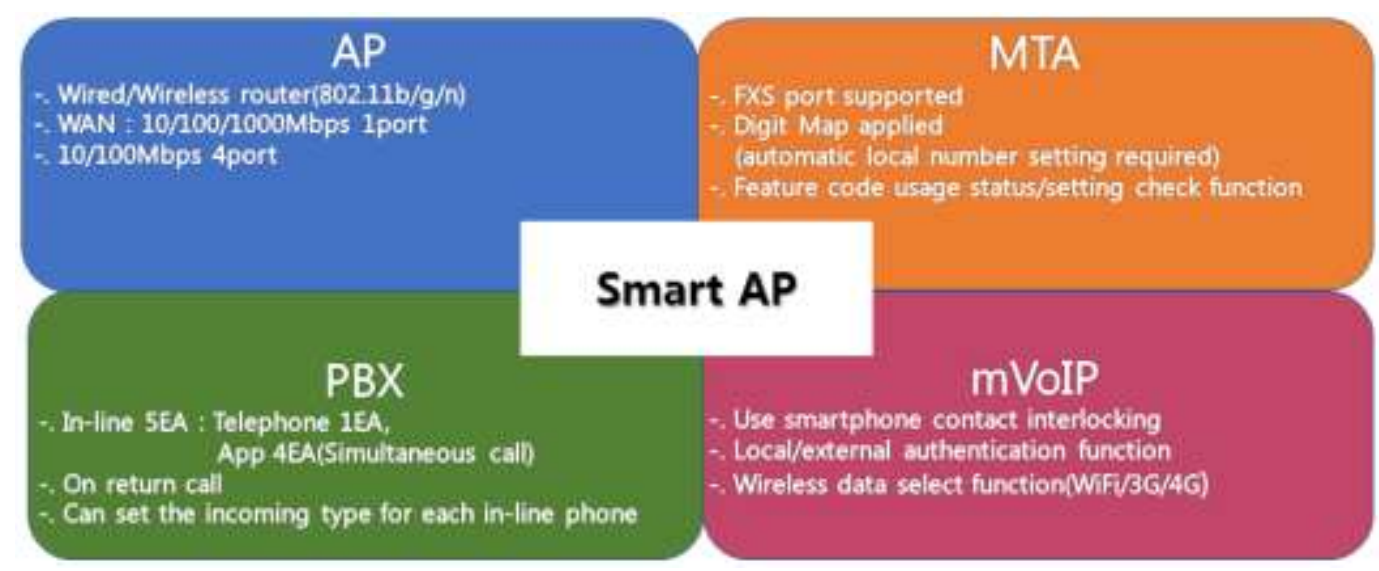

Figure 3. Functions of Smart AP

As shown in Figure 4, a home service (extension 200) connected to the Home FMC gateway or a smartphone (extension 200) equipped with the mVoIP application via WiFi can use the telephone service (incoming / outgoing with the 070-XXX-YYYY number). Outside the home, you can use a public WiFi hotspot or an LTE network to access the phone with a mVoIP application-equipped smartphone (extension 203 or 204). Home phones connected to the Home FMC gateway and smart phones with mVoIP applications (extension $201 \sim 204$ ) are also available for free extension calls. Generally, in case of a smartphone using public WiFi hotspot or LTE network, even if a smartphone with mVoIP application is registered, the limitation of telephone service is solved by using DDNS server.

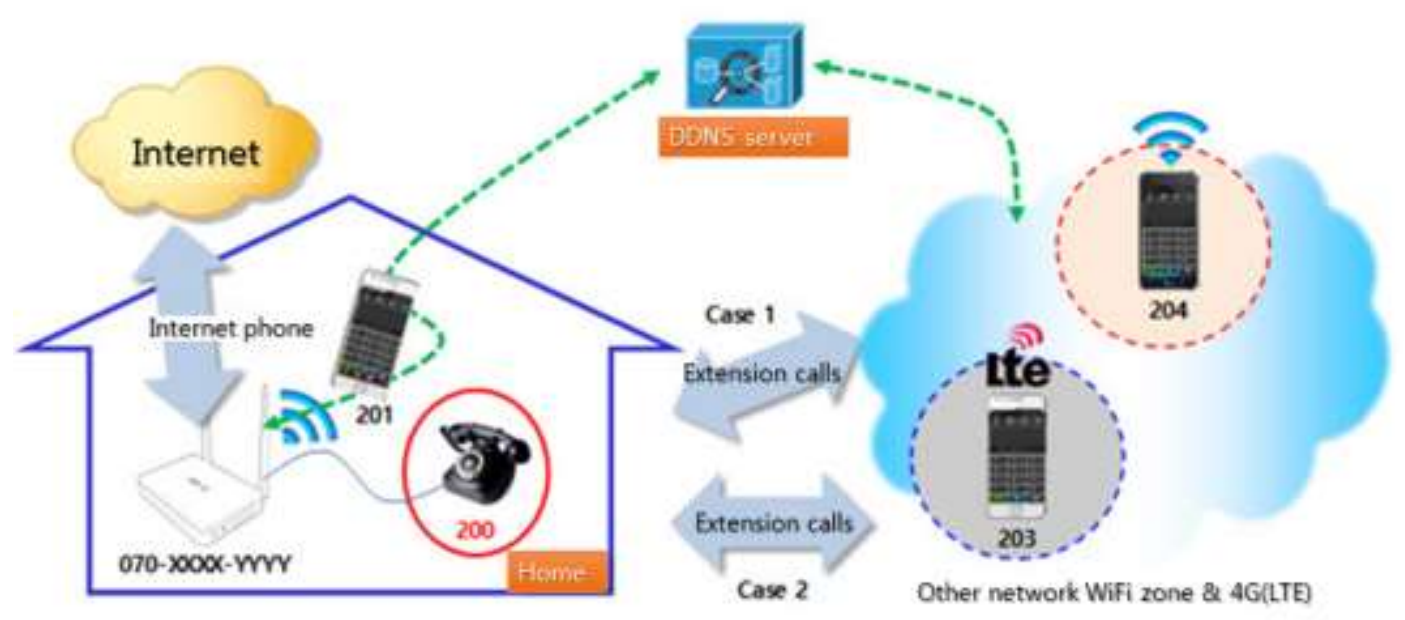

Figure 4. Service Configuration Diagram of Home FMC Gateway 


\section{Home FMC Gateway Hardware}

The hardware block diagram of the Home FMC Gateway developed in this study is shown in Figure 5.

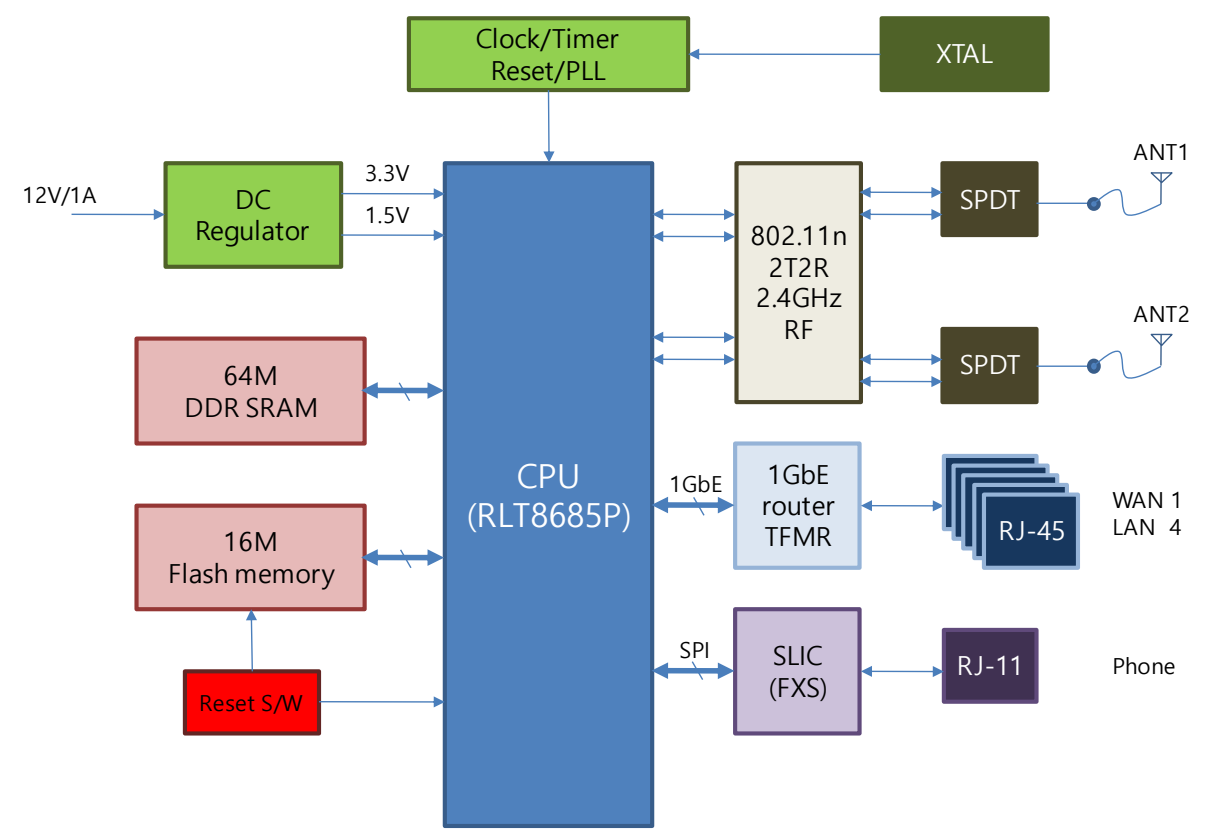

Figure 5. Home FMC Gateway Hardware Block Diagram

In order to use general telephone, CPU of higher specifications than general wired / wireless router was used and analog signal processing was performed using internal DSP core. Also, since wired internet speed is evolving to Giga service, we designed wired interface to support $1 \mathrm{GbE}$ (Gigabit Ethernet). In the case of Flash memory, considering the safety of S / W upgrading, the size of the flash memory is designed in a dual stack structure. The main block, power distribution, memory, and various interface circuits of the Home FMC gateway developed in this study are as follows.

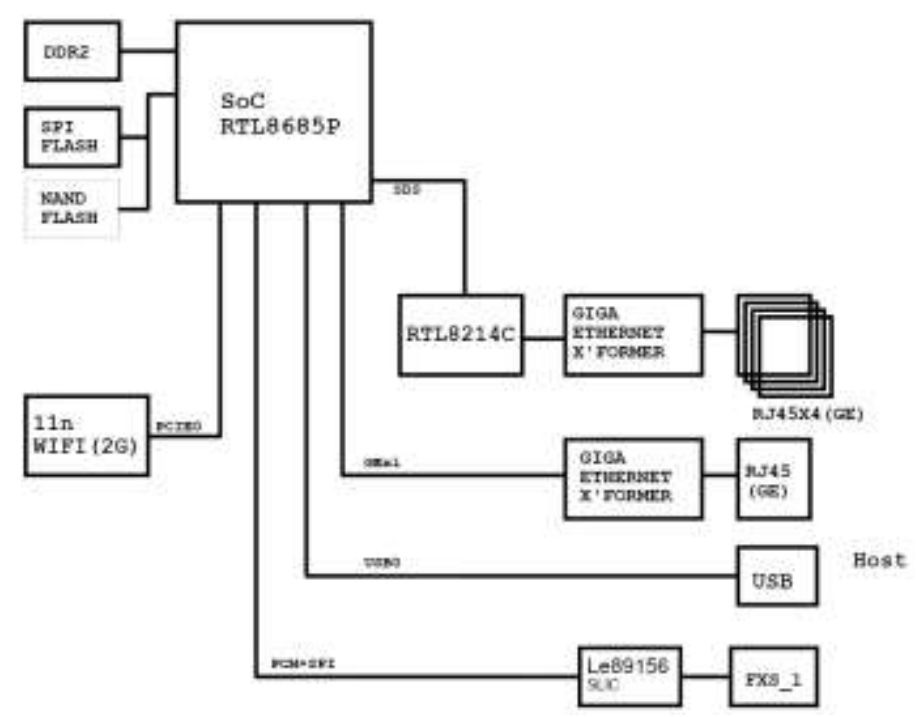

Figure 6. Main Block Design 
The voltage generation circuit through power distribution is designed as the default 12 [V] switch mode adapter, DC voltage input part, 3.3 [V] system voltage generator, $1.0[\mathrm{~V}]$ system voltage generator and 5 [V] USB voltage generator for USB.

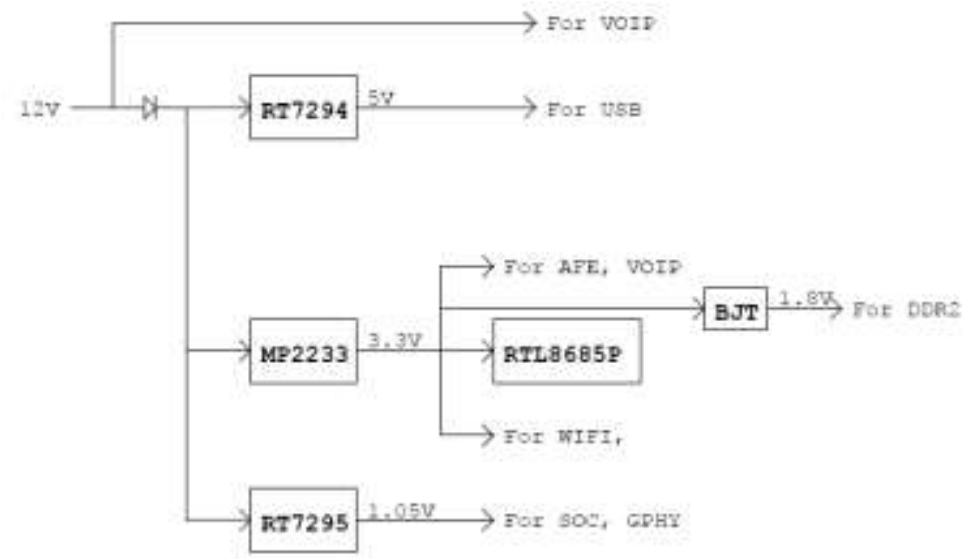

Figure 7. Power Distribution Unit Design

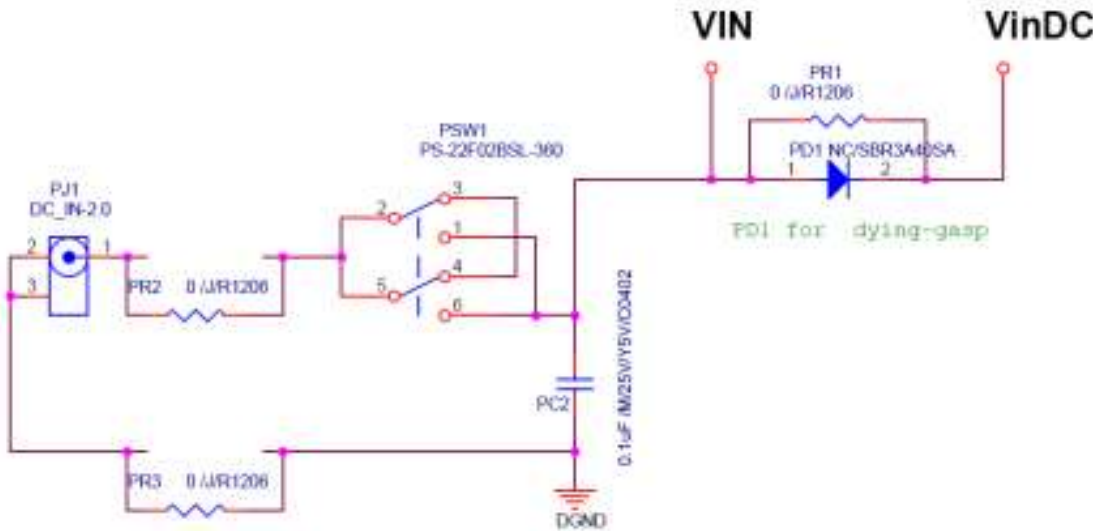

Figure 8. Default 12[V] Switch Mode Adapter Design

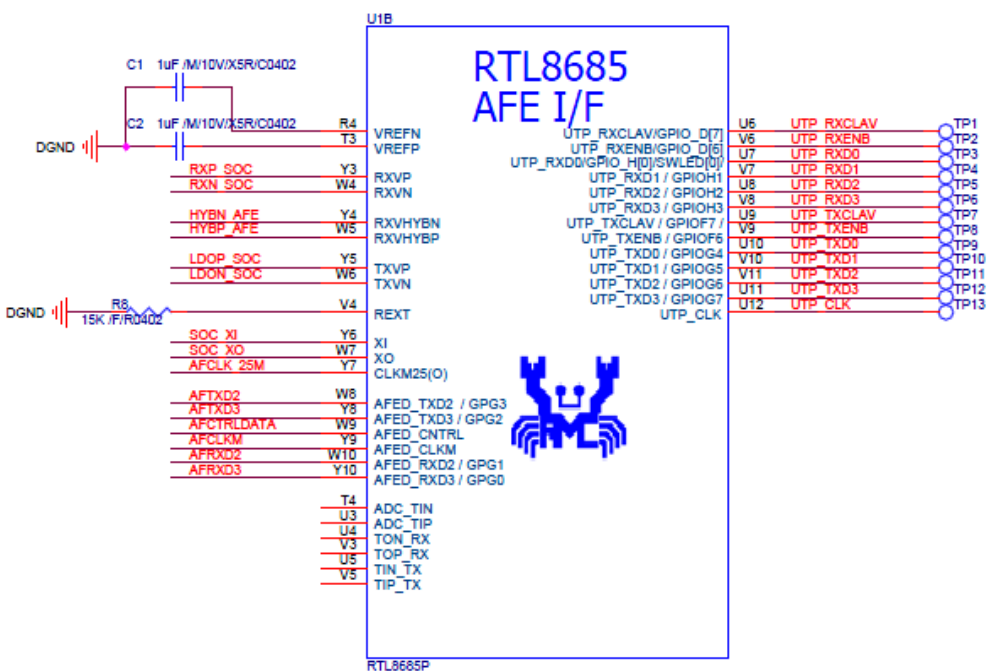

Figure 9. AFE Interface Circuit 


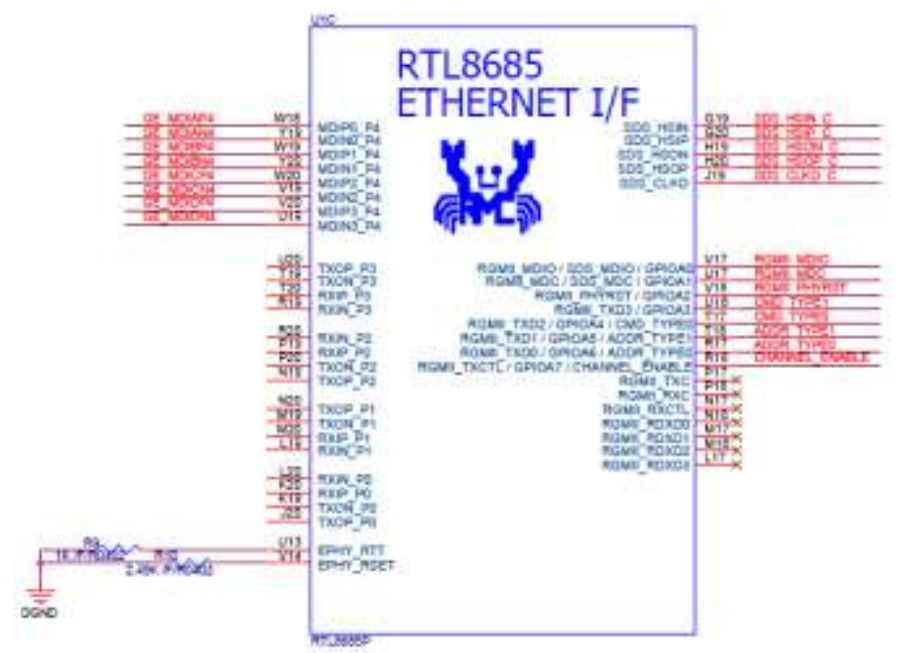

Figure 10. Ethernet Interface Circuit

The layout result of Home FMC gateway hardware designed in this research and development is as follows.
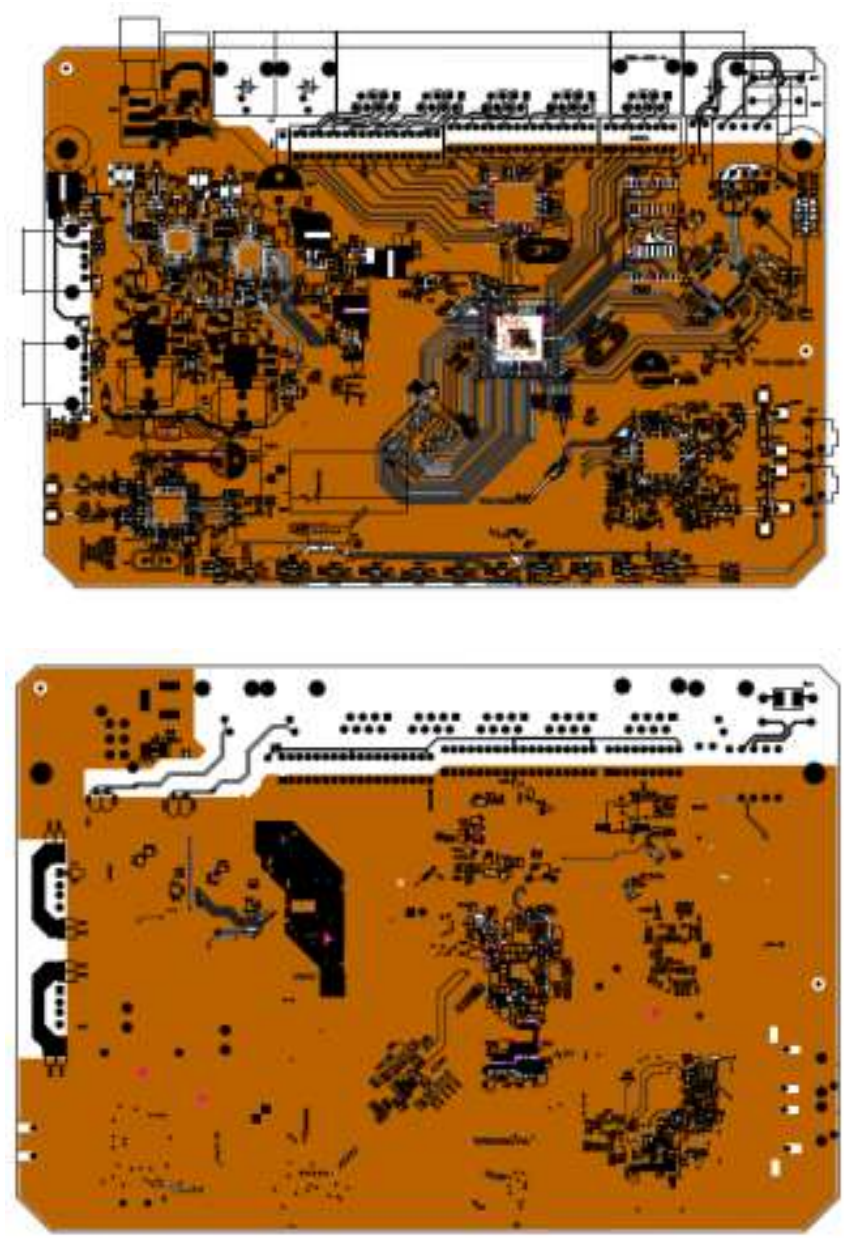

Figure 11. Top \& Bottom Layout Result of Home FMC Gateway Hardware 
Figure 12 shows the flow chart of the Home FMC Gateway APS (Auto Provisioning Server) linkage. With APS server, automatic VoIP Internet phone account creation, automatic terminal configuration, and automatic firmware upgrade are available.

- Home Power on the FMC gateway terminal. The home FMC gateway has a unique MAC for each terminal. Based on the MAC information, the home FMC gateway requests the subscriber information to the APS, and the APS provides subscriber account information, terminal configuration information, firmware download URL information, and firmware download target flag information

- Home The FMC gateway applies the subscriber account information and compares the terminal configuration information and requests the terminal configuration information file to the APS server if it is different. The APS server provides the terminal configuration information file and the terminal applies the updated configuration information

- After the Home FMC Gateway checks the firmware download target flag information (fw_update_flag), the terminal checks the upgrade target, and if it is the target, requests the firmware to the APS server with the firmware download URL information. The APS server provides the firmware so that the Home FMC gateway performs a firmware upgrade and reboots.

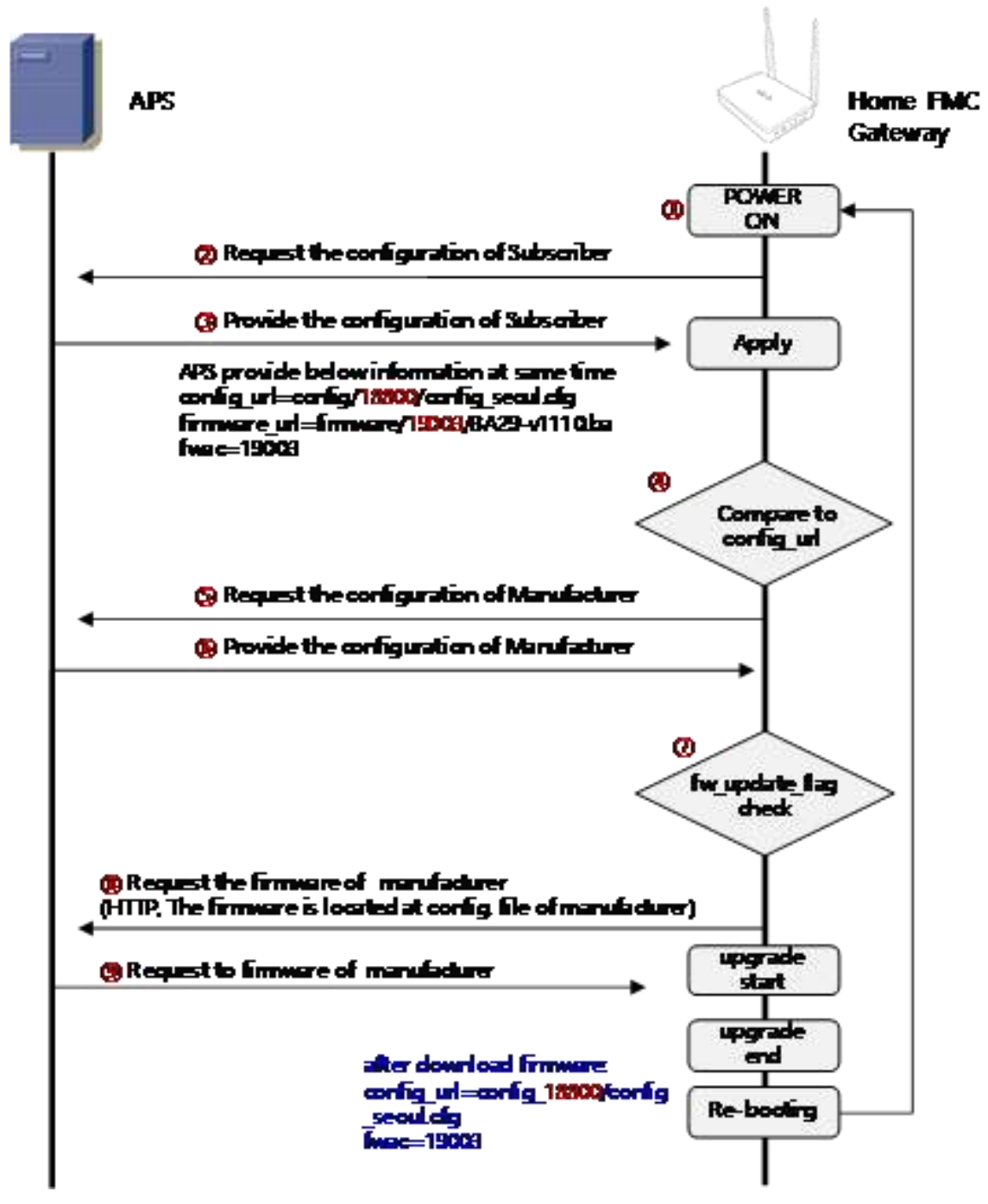

Figure 12. Flow Chart of the Home FMC Gateway APS Linkage 


\section{App Design and Development}

The mVoIP application for FMC gateway currently implements the android mVoIP application, but it needs to implement additional functions. The android mVoIP application is not a dedicated gateway but a centralized softswitch server. It can not be called or received from LTE network only for WiFi network, so it is expanded to enable communication to LTE network through gateway connection using DDNS server. Added mVoIP application-only dialer, contact and recent records, extension number and instant connection. Added mVoIP application contact search function similar to smartphone contact search.

(1) Android User Interface(Ver1.0)

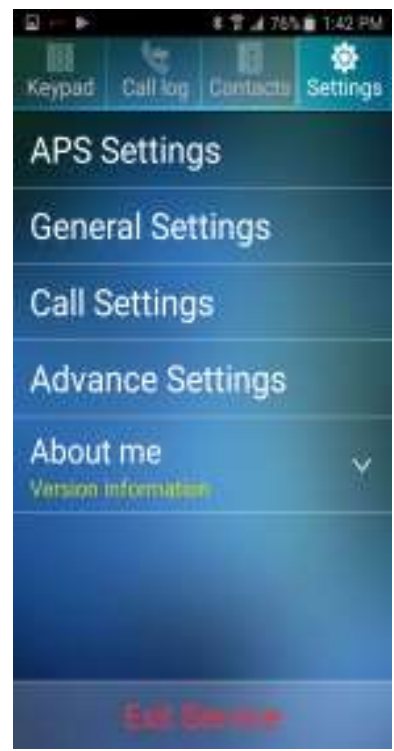

<Settings >

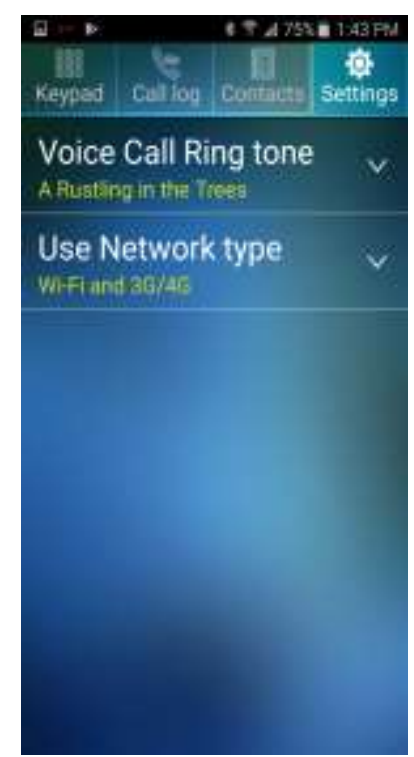

$<$ General Settings>

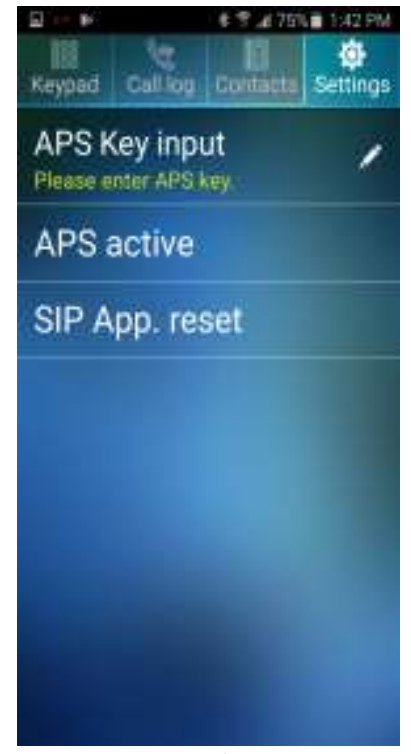

<APS Settings>

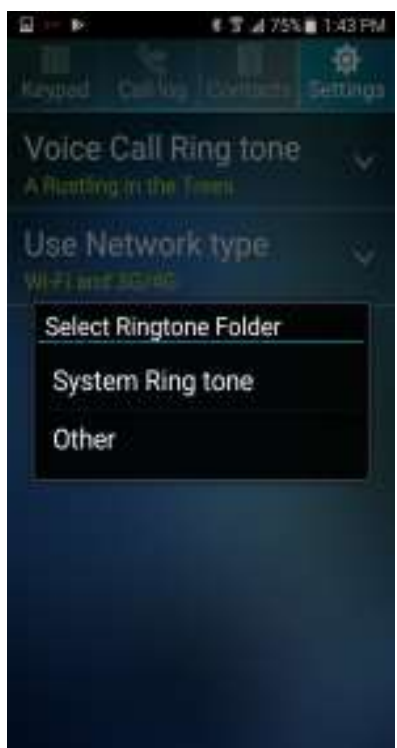

<General Settings-Ringtone>

Figure 13. Android User Interface (Ver1.0) Menu 
(2) Device User Interface

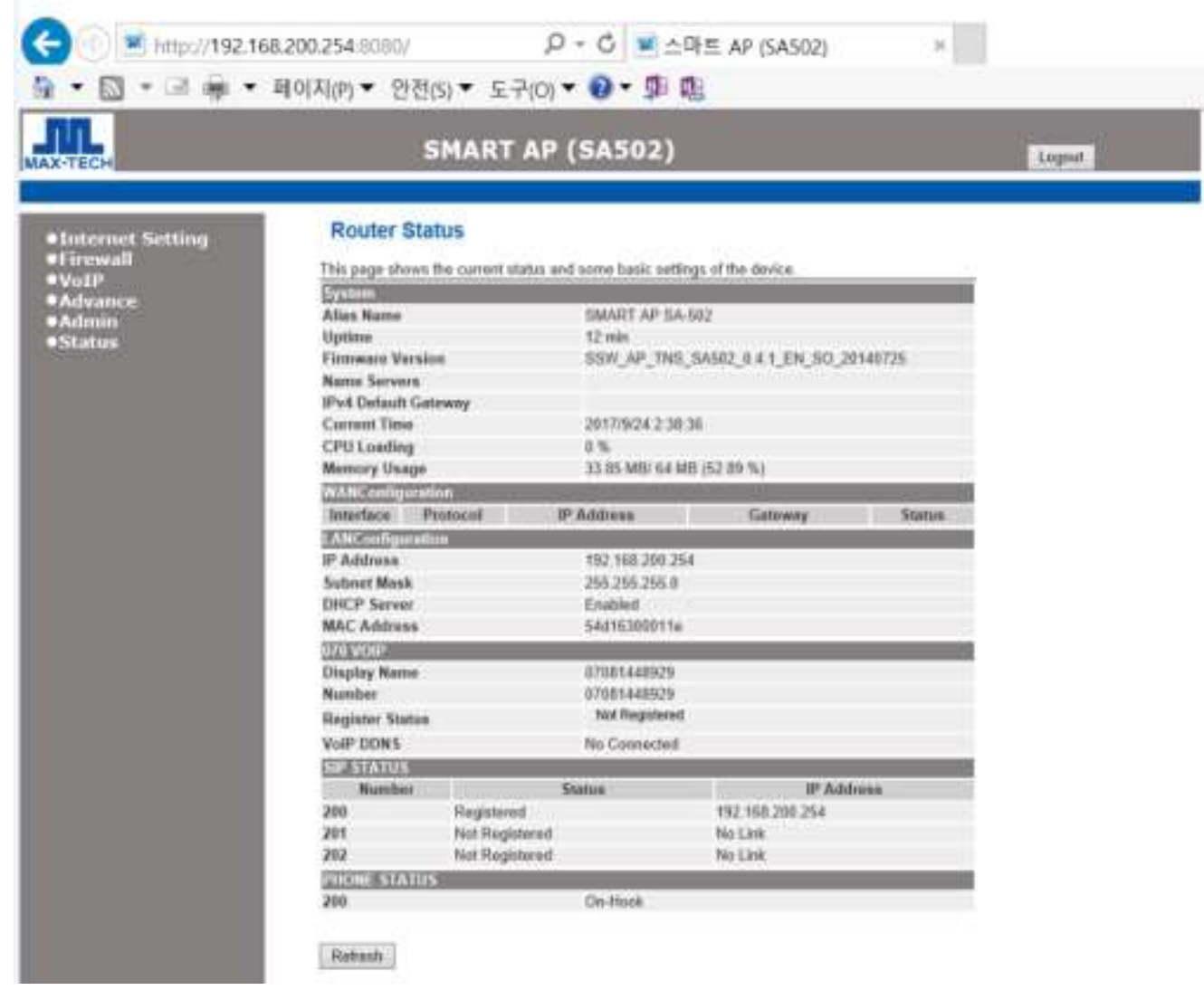

Figure 14. Device User Interface (status)

\section{Conclusion}

In this study, it is possible to install the application on the smartphone to the gateway where the domestic router and the VoIP terminal are combined according to the above-mentioned service change, and to use the wired home telephone through the gateway, and also to the mVoIP service as a home terminal. The smart AP (Access Point) developed in this study is a terminal that integrates AP + MTA + PBX + mVoIP function and developed $\mathrm{mVoIP}$ to be used in WiFi and $3 \mathrm{G}$ data network as well as LTE data network. Home FMC hardware, DDNS server, android mVoIP application were also developed. The performance analysis of the developed system is presented in Table 1 .

Table 1. Performance Analysis

\begin{tabular}{l|l|l}
\hline Performance Specification & Unit & Values \\
\hline 1. Error rate & $\mathrm{Mbps}$ & $\leq 10^{-5}$ \\
\hline 2. Electromagnetic radiation & $\mathrm{dBuV} / \mathrm{m}$ & $\leq 30 \sim 37$ \\
\hline 3. Electromagnetic wave conduction & $\mathrm{dBuV} / \mathrm{m}$ & $\leq 46 \sim 56$ \\
\hline \multirow{3}{*}{ 4. EFT/Burst } & $\mathrm{kV}$ & \pm 0.5 \\
\cline { 2 - 3 } & $\mathrm{Tr} / \mathrm{Th} \mathrm{ns}$ & $5 / 50$ \\
\cline { 2 - 3 } & $\mathrm{kHz}$ & 5 \\
\hline
\end{tabular}




\section{Acknowledgments}

Funding for this paper was provided by Namseoul University.

This paper is a revised and expanded version of a paper entitled [Study on the Home Fixed Mobile Convergence Gateway Solution] presented at [Green and Smart Technology 2017, Jeju, South Korea, December 1, 2017]

\section{References}

[1] T. Plevyak and V. Sahin, "Next Generation Telecommunications Networks, Services, and Management", WILEY, (2011).

[2] Considerations in Broadband Architecture Moving to FMC-Broadband forum, (2011), April, https://www.broadband-forum.org/marketing/download/mktgdocs/MR-235.pdf.

[3] W. Zhang, J. Wang and H. Ni, "Architecture Design of Embedded Home IMS Gateway based on Convergence of IMS and Home Network", 2008 International Conference on Embedded Software and Systems, Sichuan, China, (2008).

[4] K. Addy, "Fixed mobile convergence home control system", US 8538407 B2, September 17. US Patent, (2013).

[5] E. Doran, O. Salomon, R. Aruch and B. Goldman, "Integration of Packet and Cellular Telephone Networks", US20070291733 A1, December 20. US Patent, (2007).

[6] T. Yokotani, K. Motoshima, S. Seno and K. Kikuchi, "Sample Page Evolution of Home Networks Enhanced by Broadband Service in the Next Generation Networks", Networks 2006. 12th International Telecommunications Network Strategy and Planning Symposium, New Delhi, India, (2006).

\section{Author}

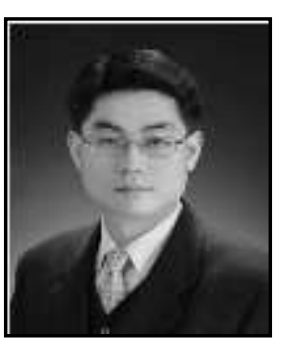

Hyoung-Keun Park, he received the M. S. and $\mathrm{Ph}$. D. degrees in electronic engineering from Wonkwang University, Iksan, Korea in 1995 and 2000, respectively. He is currently a professor department of the electronic engineering at Namseoul University, Chungnam, Korea, in 2005. His research interests are in embedded system, applied ubiquitous sensor network and network management. 